\title{
Targeted Expression of IL-11 in the Murine Airway Causes Lymphocytic Inflammation, Bronchial Remodeling, and Airways Obstruction
}

\author{
Weiliang Tang, ${ }^{\star}$ Gregory P. Geba, ${ }^{\star}$ Tao Zheng, ${ }^{\star}$ Prabir Ray, ${ }^{\star}$ Robert J. Homer, ${ }^{\ddagger \S}$ Charles Kuhn III," Richard A. Flavell," \\ and Jack A. Elias* \\ $*$ Department of Internal Medicine, Section of Pulmonary and Critical Care Medicine, ${ }^{\ddagger}$ Department of Pathology, and ${ }^{\|}$Department of \\ Immunobiology, Yale University School of Medicine, New Haven, Connecticut 06520; ${ }^{\S}$ A-CT Health Care System, West Haven, \\ Connecticut 06516; and "Department of Pathology, Brown University School of Medicine, Memorial Hospital of Rhode Island, \\ Pawtucket, Rhode Island 02860
}

\begin{abstract}
Interleukin-11 is a pleotropic cytokine produced by lung stromal cells in response to respiratory viruses, cytokines, and histamine. To further define its potential effector functions, the Clara cell $10-\mathrm{kD}$ protein promoter was used to express IL-11 and the airways of the resulting transgene mice were characterized. In contrast to transgene $(-)$ littermates, the airways of IL-11 transgene $(+)$ animals manifest nodular peribronchiolar mononuclear cell infiltrates and impressive airways remodeling with subepithelial fibrosis. The inflammatory foci contained large numbers of $\mathrm{B} 220(+)$ and MHC Class $\mathrm{II}(+)$ cells and lesser numbers of CD3(+), CD4(+), and CD8 $(+)$ cells. The fibrotic response contained increased amounts of types III and I collagen, increased numbers of $\alpha$ smooth muscle actin and desmin-containing cells and a spectrum of stromal elements including fibroblasts, myofibroblasts, and smooth muscle cells. Physiologic evaluation also demonstrated that 2-mo-old transgene $(+)$ mice had increased airways resistance and non-specific airways hyperresponsiveness to methacholine when compared with their transgene (-) littermates. These studies demonstrate that the targeted expression of IL-11 in the mouse airway causes a $B$ and $T$ cell-predominant inflammatory response, airway remodeling with increased types III and I collagen, the local accumulation of fibroblasts, myofibroblasts, and myocytes, and obstructive physiologic dysregulation. IL-11 may play an important role in the inflammatory and fibrotic responses in viral and/or nonviral human airway disorders. (J. Clin. Invest. 1996. 98:2845-2853.) Key words: epithelial cell $\bullet$ fibrosis $\cdot$ cytokine $\cdot$ myofibroblast • collagen
\end{abstract}

\section{Introduction}

Obstructive airways disorders are a major cause of morbidity and mortality, with asthma affecting $\sim 9-12$ million people $(1,2)$, chronic obstructive pulmonary disease $(\mathrm{COPD})^{1}$ affecting 12-14 million people (3), and bronchiolitis and bronchiectasis affecting large numbers of people $(4,5)$ in the

Address correspondence to Jack A. Elias, Yale University School of Medicine, Section of Pulmonary and Critical Care Medicine, Department of Internal Medicine, 333 Cedar Street, 105 LCI, New Haven, CT 06520. Phone: 203-785-4163; FAX: 203-785-3826.

Received for publication 30 May 1996 and accepted in revised form 10 October 1996.

The Journal of Clinical Investigation

Volume 98, Number 12, December 1996, 2845-2853
United States alone. Chronic airway inflammation and airway remodeling (defined as fibrosis, matrix alterations, and/or changes in structural or resident cells of the airway wall) are important features of these disorders (3-11). However, the pathogenetic mechanisms that generate these responses and the relationship between these responses and the physiologic dysregulation characteristic of these disorders are poorly understood.

Respiratory viruses play an important role in obstructive disorders of the human airway. Viruses are important precipitants of asthmatic exacerbations $(6,12-15)$ and may similarly exacerbate COPD (16). In addition, epidemiologic investigations have demonstrated important associations between infantile viral infections and the existence of asthma $(12,13,17,18)$, and pediatric infections and COPD $(16,19)$ in later life. These viral effects are felt to be mediated via a number of mechanisms, including the induction and modulation of local inflammation $(10,12,20)$. Virus-stimulated cytokine production is increasingly understood to play a prominent role in the generation of these inflammatory abnormalities $(6,21-23)$. The contribution(s) that each virus-stimulated cytokine makes to the pathologic and physiologic abnormalities characteristic of viral infections in hosts with normal and obstructed airways has, however, been inadequately investigated. In addition, we know little about the mechanism(s) by which pediatric viral infections and virus-induced cytokines predispose to airways disorders in later life.

IL-11 was initially discovered as a plasmacytoma proliferation stimulating activity in supernatants from transformed marrow fibroblasts $(24,25)$. In accordance with this finding, most studies of IL-11 have focused on its roles in hematopoiesis (25). IL-11 has, however, been shown to have a variety of other bioactivities, including the ability to stimulate the acute phase response (25), augment the production of metalloproteinase inhibitors $(26,27)$, increase immunoglobulin production $(25,28)$, and alter neural phenotype (29). Previous studies from our laboratory demonstrated that human lung fibroblasts and epithelial cells produce IL-11 in response to cytokines (IL-1 and TGF- $\beta_{1}$ ), histamine, and viruses that have been epidemiologically associated with asthmatic exacerbations (rhinovirus, respiratory syncytial virus [RSV], and parainfluenza virus type 3, [PIV3]) (21, 30, 31). Our studies have also demonstrated that IL-11 can be found in the nasal secretions of children with viral upper respiratory tract infections and that IL-11 induces

1. Abbreviations used in this paper: AHR, airways hyperresponsiveness; $\mathrm{BAL}$, bronchoalveolar lavage; $\mathrm{CC} 10$, clara cell $10-\mathrm{kD}$ protein; COPD, chronic obstructive pulmonary disease; $\mathrm{MCh}$, methacholine; PIV3, parainfluenza virus type 3; RSV, respiratory synctial virus. 
airways hyperresponsiveness (AHR) when inhaled in a transient fashion into murine lungs (23). As a result of these observations, we postulated that IL-11 plays an important role in the pathogenesis of human airway disorders, particularly those that are associated with viral infections.

In keeping with the chronic nature of disorders such as asthma, COPD, bronchiectasis, and bronchiolitis, we addressed this hypothesis by defining the respiratory tract manifestations of IL-11 when chronically present in the respiratory tract. This was done by generating and evaluating the airways of transgenic mice in which the Clara cell $10-\mathrm{kD}$ protein $(\mathrm{CC} 10)$ promoter was used to target IL-11 to the respiratory tree. These studies demonstrate that IL-11 causes impressive airway alterations with transgene $(+)$ animals manifesting a nodular B and $\mathrm{T}$ cell-predominant peribronchiolar inflammatory response, bronchial remodeling with subepithelial fibrosis, and physiologic dysfunction characterized by airways obstruction and nonspecific AHR.

\section{Methods}

Production and identification of transgenic mice. To study the effector functions of IL-11 in the airway, we took advantage of the fact that the murine respiratory tract epithelium contains $50-60 \%$ clara cells $(32,33)$. As previously described $(32)$, we used the promoter of the $\mathrm{CC} 10$ gene to target the expression of human IL-11 to airway tissues. The rat CC10 promoter was a gift of Drs. Barry Stripp and Jeffrey Whitsett (34). It was isolated as a $2.3-\mathrm{kb}$ HindIII fragment and subcloned into the HindIII site of construct pKS-SV40, yielding construct pKS-CC10-SV40. pKS-SV40 had been previously prepared by inserting a $0.85-\mathrm{kb} \mathrm{BglII} / \mathrm{BamHI}$ fragment containing SV40 intronic and polyadenylation sites into the BamHI site in construct pBluescript IIKS (Stratagene Inc., La Jolla, CA). The cDNA encoding human IL-11 was a generous gift of Dr. Paul Schendel (Genetics Institute, Cambridge, MA). It was isolated as a 1.2-kb EcoRI fragment, end filled with Klenow enzyme and subcloned into the EcoRV site in pKS-CC10-SV40 using standard techniques. All constructs were checked for correct orientation of the inserts by restriction enzyme digestion, and junction sequences were confirmed by sequencing. The resulting CC10-IL-11-SV40 construct was purified, digested with Asp 718 and BamHI to generate the CC10-IL-11-SV40 fragment (Fig. 1), separated by electrophoresis through $1 \%$ agarose, and isolated by electroelution into dialysis tubing. The DNA fragment was then purified through Elutip-D columns following the manufacturer's instructions (Schleicher and Schuell, Inc., Keene, NH) and dialyzed against injection buffer $(0.5 \mathrm{mM}$ Tris- $\mathrm{HCl} / 25 \mathrm{mM}$ EDTA, $\mathrm{pH} 7.5)$. Transgenic mice were prepared in $(\mathrm{CBA} \times \mathrm{C} 57 \mathrm{BL} / 6) \mathrm{F}_{2}$ eggs using standard pronuclear injection as previously described $(32,35)$. The presence or absence of the transgene was evaluated in offspring animals using tail-derived DNA. This was initially done by Southern blot analysis using ${ }^{32} \mathrm{P}$-labeled IL-11 cDNA as a probe. Similar results were obtained by PCR using 5'-CGACTGGACCGGCTGCTGC-3' and 5'-CTAACTAGGGGGAGATAATGGCGGGGGGA-3' as upper and lower primers, respectively. 35 cycles were performed. Each cycle was heated at $95^{\circ} \mathrm{C}$ for $1 \mathrm{~min}$, annealed at $63^{\circ} \mathrm{C}$ for $1 \mathrm{~min}$, and elongated at $72^{\circ} \mathrm{C}$ for $2 \mathrm{~min}$.

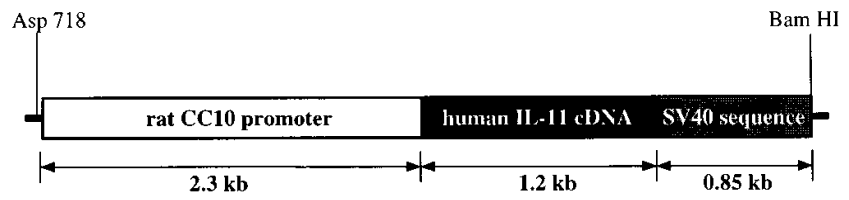

Figure 1. Schematic illustration of CC10-IL-11 construct used in the preparation of the transgenic mice described in this manuscript.
Bronchoalveolar lavage and quantification of IL-11 levels. Mice were killed via cervical dislocation, a median sternotomy was performed, blood was obtained via right heart puncture and aspiration, and serum was prepared. The trachea was then isolated via blunt dissection and small caliber tubing was inserted and secured in the airway. Three successive washes of $0.75 \mathrm{ml}$ PBS with $0.1 \%$ BSA were then instilled and gently aspirated. Each bronchoalveolar lavage (BAL) aliquot was centrifuged and the supernatants were harvested and stored individually at $-70^{\circ} \mathrm{C}$ until ready to be used. The levels of IL-11 in the BAL fluid and serum were quantitated immunologically via ELISA and biologically using the B9.11 plasmacytoma proliferation bioassay. The ELISA was performed as previously described by our laboratory $(21,30)$ using antibodies $11 \mathrm{~h} 3 / 15.6 .1$ and $11 \mathrm{~h} 3 / 19.6 .1$ provided by Dr. Edward Alderman (Genetics Institute). The bioassay was also performed as previously described by our laboratory $(36,37)$ using B9.11 cells also provided by Genetics Institute. Since both IL-6 and IL-11 can stimulate B9.11 cell proliferation, this assay was performed in the presence and absence of neutralizing antibodies against IL-11 (a gift of Dr. Alderman) and IL-6 (a gift of Dr. Pravin Sehgal, New York Medical College, Valhalla, NY) to assess the relative contribution of each of these moieties.

Northern analysis. Total cellular RNA from a variety of mouse tissues was obtained using guanidine isothiocyanate extraction and formaldehyde-agarose gel electrophoresis as previously described $(21,30)$. IL-11 gene expression was assessed by probing with ${ }^{32} \mathrm{P}$ labeled IL-11 cDNA. Equality of sample loading and efficiency of transfer were assessed via ethidium bromide staining.

Histologic evaluation. Animals were killed via cervical dislocation, median stenotomies were performed, and right heart perfusion was accomplished with calcium and magnesium-free PBS to clear the intravascular space. The heart and lungs were then removed en bloc, inflated with $1 \mathrm{cc}$ neutral buffered $10 \%$ formalin, fixed overnight in $10 \%$ formalin, embedded in paraffin, and sectioned and stained. Hematoxylin and eosin, and Mallory's trichrome stains were performed.

Morphometric analysis. Morphometric study was carried out on mice aged $15 \mathrm{~d}, 1 \mathrm{mo}$, and $2 \mathrm{mo}$. The thickness of the walls of small airways from the base of the columnar epithelium to the outer limit of the adventitia was measured using an eye-piece reticle. Bronchioles $<250 \mu \mathrm{m}$ in diameter that presented a closed circular or oval profile were selected and all measurements were made at 400 magnification to the nearest whole micrometer. The wall thickness was routinely evaluated at two points on opposite sides of the short axis of the elliptical profiles and measurements were made at locations where cell borders appeared sharp to minimize tangential sectioning. 5-12 airways were measured per mouse, mean 8.4. The presence or absence of lymphoid nodules was recorded for each bronchiolar profile, whether or not it was considered appropriate for measuring wall thickness. Statistical evaluations of the morphometric results were performed by the Bonferonni multiple comparisons test using Instat software for the Macintosh.

Immunohistochemistry. Animals were killed, the vascular tree was perfused, and the heart and lungs were removed en bloc as described above. The tissues were then processed using a number of approaches. For evaluations of cell surface markers and subepithelial airway cellularity, lungs were inflated with $1 \times \mathrm{PBS} / 33 \%$ (vol $/ \mathrm{vol})$ OCT tissue-tek compound (Miles Laboratories, Inc., Elkhart, IN) and snap frozen in OCT by submersion into 2-methylbutane cooled with dry ice. Tissue sections were cut, transferred onto silane-treated glass slides, fixed with acetone for $15 \mathrm{~min}$, and stained with various antibody reagents as previously described (32). Sections were blocked with avidin-blocking kit (Vector Laboratories, Inc., Burlingame, CA) and BSA before reaction with the desired biotinylated primary antibody. The slides were then washed three times (in $0.1 \mathrm{M}$ Tris buffer, $\mathrm{pH}$ 7.5) and the tissue sections were incubated with a prediluted streptavidin-alkaline phosphatase solution (Vector Laboratories, Inc.) for $1 \mathrm{~h}$. The sections were washed and developed using Vector red staining (Vector Laboratories, Inc.) in accordance with the manufacturer's instructions. The slides were counter stained with 
Meyer's hematoxylin, and then mounted with aqueous histologic mounting medium (Zymed Laboratories, Inc., So. San Francisco, CA).

For types I and III collagen immunostaining, mouse lungs were chilled in acetone containing protease inhibitors $(20 \mathrm{mM}$ iodoacetamide and $2 \mathrm{mM}$ phenylmethyl sulfonyl fluoride) at $-20^{\circ} \mathrm{C}$ for $16-20 \mathrm{~h}$. The lungs were then chopped into $\sim 2 \times 5 \times 6 \mathrm{~mm}^{3}$ pieces and immersed three times in glycol methacrylate (GMA) monomer at $4^{\circ} \mathrm{C}$ for $6 \mathrm{~h}$. The samples were then embedded in GMA according to the manufacturer's instructions (JB4 Embedding Kit; Polysciences Inc., Warrington, PA) and 2- $\mu \mathrm{m}$ sections were cut and transferred onto silane-treated glass slides. Immunohistochemical staining was undertaken as described above except that sections were treated with $1 \mathrm{M}$ citric acid ( $\mathrm{pH} 3.0$ ) for $2 \mathrm{~h}$ before staining, and primary antibody incubation took place at $4^{\circ} \mathrm{C}$ overnight.

The antibodies that were employed and their sources are listed below. They included antibodies to CD3, CD4, CD8 (Gibco Laboratories, Grand Island, NY), Mac-1 (Pharmingen, San Diego, CA), B220 (Pharmingen), MHC Class II (a gift from Dr. Kim Bottomly, Yale University), type I collagen (Chemicon International, Inc., Temecula, CA), type III collagen (a gift from Dr. J. Madri, Yale University), $\alpha$-smooth muscle actin (Sigma Chemical Co., St. Louis, MO), and desmin (Sigma Chemical Co.).

Electron microscopy. Fragments of lung from three age- and sexmatched littermate pairs were fixed in 3\% gluteraldehyde, postfixed in osmium tetroxide, and embedded in Epox 812 (Ernest F. Fulham, Inc., Latham, NY). Tissues were then cut onto grids, stained with uranyl acetate and lead nitrate, and examined in a Philips 300 microscope (Philips Electronic Instruments, Inc., Mahwah, NJ).

Physiologic evaluation of transgenic mice. Age, sex, and weight matched littermate mice were anesthetized with pentobarbital (90 $\mathrm{mg} / \mathrm{kg}$ ) and tracheostomized with an 18-gauge angiocatheter. Airways resistance was then measured using a modification of the techniques described by Martin et al. (38) as previously described (32). With these techniques, the changes in the lung volumes of anesthetized and tracheostomized mice were measured plethysmographically by determining the pressure in a Plexiglass chamber using an inline microswitch pressure transducer. Flow was measured by differentiation of the volume signal and transpulmonary pressure was determined via a second Microswitch pressure transducer placed in line with the plethysmograph and animal ventilator. Resistance was then calculated using the method of Amdur and Mead (39). The resistance of the tracheostomy catheter was routinely eliminated. Baseline measurements of pulmonary resistance were obtained by ventilating the mouse in the plethysmograph at volumes of $0.4 \mathrm{ml}$ at a rate of 150 breaths per minute (settings previously shown to produce normal arterial blood gases in this species) (38). Bronchial reactivity was also assessed using noncumulative methacholine challenge procedures as previously described by our laboratory (32). In this procedure, increasing concentrations of methacholine (MCh) in PBS were administered by nebulization (20 one-ml breaths) using a Devilbiss Aerosonic nebulizer (Model 5000; DeVilbiss Health Care, Somerset, PA) that produces particles 1-3 $\mu \mathrm{M}$ in diameter. Pulmonary resistance was calculated precisely $1 \mathrm{~min}$ later. Stepwise increases in MCh dose were then given until the pulmonary resistance, in comparison with the baseline level, had at least doubled. All animals received serial threefold increases in MCh from 1 to $100 \mathrm{mg} / \mathrm{ml}$. The data are expressed as the $\mathrm{PC}_{100}$ (provocative challenge 100), the dose at which pulmonary resistance was $100 \%$ above the baseline level as calculated by linear regression analysis.

Statistical analysis. Values are expressed as means \pm SEM. Unless otherwise noted, group means are compared with the Student's two tailed unpaired $t$ test using the StatView software for the Macintosh.

\section{Results}

Generation of transgenic mice. To generate transgenic mice in which IL-11 is overproduced in a lung-specific/selective fash-
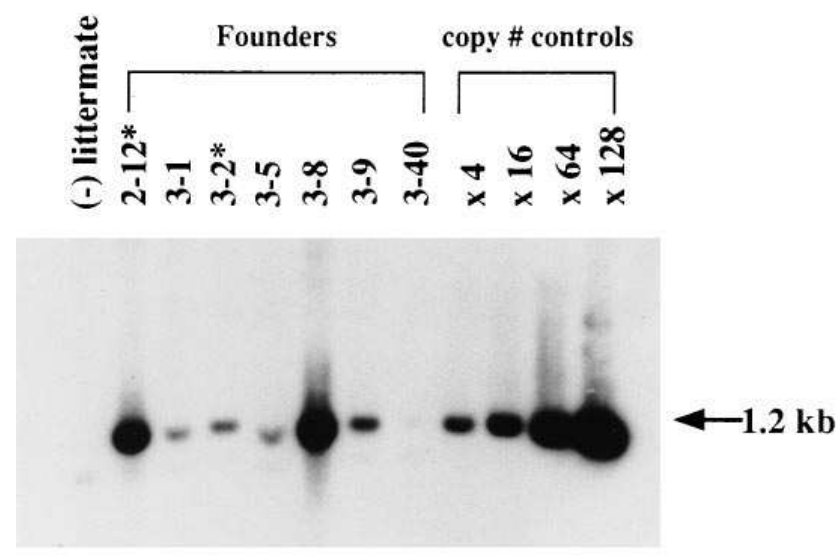

\section{$\begin{array}{lllllllllllll}1 & 2 & 3 & 4 & 5 & 6 & 7 & 8 & 9 & 10 & 11 & 12\end{array}$}

Figure 2. Southern blot analysis of CC10-IL-11 mice. Tail DNA was obtained and the presence or absence of the CC10-IL-11 construct was determined using Southern blot analysis as described in Methods. The results obtained using tail DNA from transgene $(+)$ founder animals (lanes 2-8) are compared with a transgene (-) littermate (lane 1) and copy number control (lanes 9-12).

ion, pronuclear microinjections of the CC10-IL-11-SV40 construct were performed on two separate occasions. From these microinjections, seven animals with transgene copy numbers varying between 1 and 70 were obtained (Fig. 2). These founder animals were bred with C57 BL/6 mice and the transgene status of these offspring were similarly analyzed. This analysis demonstrated that the transgenes passed on to the off-

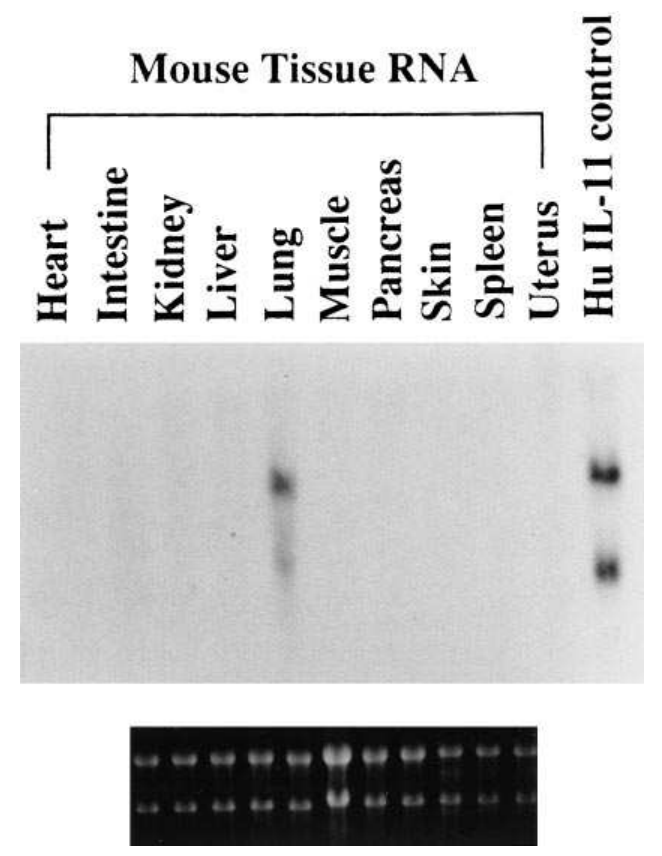

Figure 3. Northern blot analysis of IL-11 mRNA expression in mouse organs. Total cellular RNA was isolated from the noted organs of transgene (+) CC10-IL-11 mice and the levels of IL-11 mRNA characterized using Northern blot analysis as described in Methods. The IL-11 mRNA in total cellular RNA from the different tissues is compared with the IL- 11 mRNA in TGF- $\beta_{1}(10 \mathrm{ng} / \mathrm{ml})$-stimulated human lung fibroblasts $(\mathrm{Hu} I L-11 \mathrm{control})$. Ethidium bromide controls are in bottom panel. 


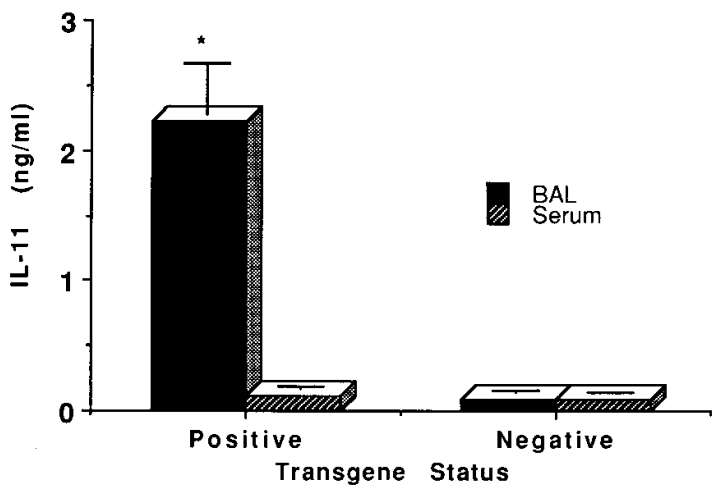

Figure 4. Levels of immunoreactive IL-11 in BAL fluid and serum of transgene $(+)$ and $(-)$ littermates. The noted values represent the mean \pm SEM of the evaluations of four separate pairs of transgene $(+)$ and $(-)$ littermates $(* P<0.01$ vs. serum of transgene $(+)$ animals and BAL and serum of transgene $(-)$ animals; paired $t$ test).

spring of these founder animals in a Mendelian fashion. Of these founders, lines 2-12 and 3-2 were chosen for more extensive analysis. Since they manifest similar pathologic, immunologic, and physiologic abnormalities, they will be discussed in a unified fashion.

Organ specificity and intensity of IL-11 gene expression and protein production. To determine if the CC10-IL-11 transgene was appropriately expressed, Northern analysis was used to compare the levels of IL-11 mRNA in the lungs and extrapulmonary organs of transgene $(+)$ and $(-)$ littermates. IL-11 mRNA was readily detected in the lungs of transgene $(+)$ animals, but could not be appreciated in the lungs of transgene $(-)$ animals (Fig. 3 and data not shown). In accordance with in vitro studies using fibroblasts and epithelial cells $(21,30)$, this IL-11 mRNA appeared to have one major and one minor transcript. IL-11 gene expression also appeared to be appropriately targeted to the lung since human IL-11 mRNA was not detectable in the RNA from a variety of extrapulmonary organs (Fig. 3). In all cases, IL-11 mRNA appeared to be appropriately translated since IL-11 was easily detected immunologically and biologically in the BAL fluid of the transgene $(+)$ animals, but not in the serum of transgene $(+)$ animals or the serum or BAL fluid of transgene (-) littermates (Fig. 4 and Table I).

Table I. IL-11 Bioactivity in BAL Fluids From Transgene (+) and (-) Animals

\begin{tabular}{lcc}
\hline & \multicolumn{2}{c}{$\left[{ }^{3} \mathrm{H}\right]-$ Tdr incorporation ${ }^{\ddagger}$} \\
\cline { 2 - 3 } Incubation conditions* & No antibody & + Anti-IL-11 \\
\hline BAL $(-)$ & $3,178 \pm 3,708$ & $1,705 \pm 166$ \\
BAL $(+)$ & $57,383 \pm 5,351$ & $5,568 \pm 378$ \\
BAL $(+)$ & $52,960 \pm 4,717$ & $6,189 \pm 5,507$ \\
Negative control & $1,896 \pm 101$ & -
\end{tabular}

*BAL were performed on transgene $(+)$ and $(-)$ littermate $\mathrm{F}_{2}$ progeny of IL-11 transgenic mice. ${ }^{\ddagger} \mathrm{B} 9.11$ plasmacytoma $\left[{ }^{3} \mathrm{H}\right]$-Tdr incorporation assessed in the presence and absence of anti-IL-11. BAL plasmacytoma-stimulating activities are compared with the proliferation $\left(\left[{ }^{3} \mathrm{H}\right]-\mathrm{Tdr}\right.$ incorporation) of B9.11 cells incubated in medium alone (negative control). Values represent the mean \pm SEM of triplicate determinations.

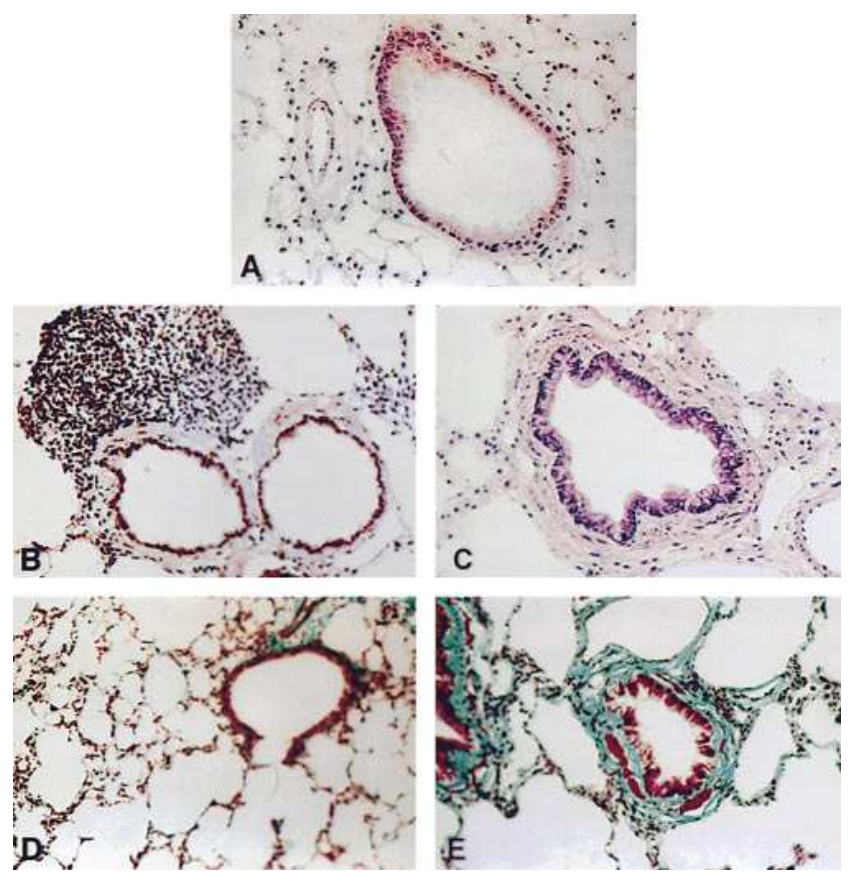

Figure 5. Histologic abnormalities in airways of CC10-IL-11 transgenic mice. The lungs of transgene $(+)$ and $(-)$ animals were removed, fixed, and evaluated using hematoxylin and eosin and trichrome stains. The histologic appearance of the transgene $(-)$ mouse lung $(A)$ is compared with the peribronchiolar lymphocytic infiltrates and bronchiolar thickening in the transgene $(+)$ animals $(B$ and $C$ ). The collagen content of the lungs of transgene $(-)$ animals appears in green in $D$. This contrasts with the impressive subepithelial fibrosis seen in the airways of transgene $(+)$ animals $(E)$. (Original magnification $67.5 \times$.)

Effect of IL-11 on murine airways. Progeny mice were killed at various intervals between 0.5 and 2 mo of age, and the airways of transgene $(+)$ and $(-)$ littermates were compared. A total of 78 age and sex matched littermate pairs were evaluated. In contrast with their transgene $(-)$ littermates, the transgene $(+)$ animals manifest an impressive airway phenotype composed of: (a) nodular collections of lymphocyte-like cells next to bronchi and bronchioles, and (b) airway wall thickening and remodeling (Fig. 5, $A-C$ ). The collections of lymphocytes were appreciated less often in the 0.5 -mo-old animals, but were prominently noted in the 1- and 2-mo-old animals (data not shown). The impressive and progressive effects of IL-11 on the thickness of the airway wall were easily seen in the morphometric evaluations (Fig. 6). Insight into the cause of this thickening and remodeling was obtained from the trichrome evaluations. These stains demonstrated only small amounts of collagen in the lungs of transgene $(-)$ animals. This contrasted with the extensive subepithelial fibrosis seen in the airways of the IL-11 transgene (+) animals (Fig. 5, $D$ and $E$ ).

Composition of peribronchiolar nodules. The results noted above demonstrate that IL-11 overexpression in the murine airway generates nodular collections of lymphocyte-like mononuclear cells. The phenotype of these cells was, therefore, analyzed by immunohistochemistry using frozen lung sections. These studies demonstrated that the majority of the cells in these nodules were MHC Class II (+) and B220 (+) (Fig. 7). Collections of CD3(+), CD4(+), and CD8 $(+)$ cells were also noted (Fig. 6). Significant Mac-1 immunoreactivity was not 


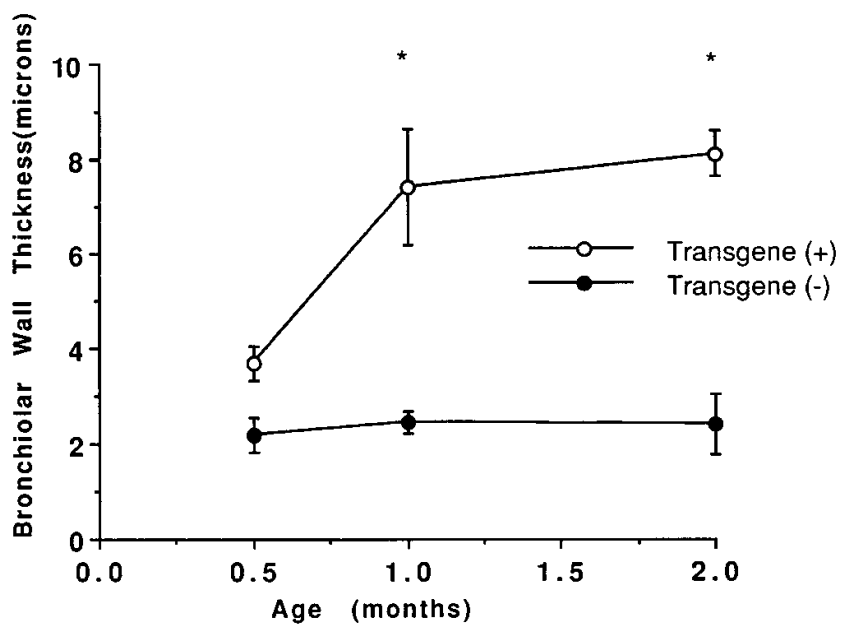

Figure 6. Morphometric analysis of airway wall thickening of CC10-IL-11 animals. The thickness of the bronchioles of 0.5-, 1-, and 2-mo-old transgene $(+)$ and $(-)$ littermates were measured as described in Methods. Values represent the mean \pm SEM of at least three pairs of animals at each time point $\left({ }^{*} P<0.001\right.$ Bonferonni Multiple comparisons test).

appreciated with only a rare cell staining with this antibody (Fig. 7). None of the antibodies that were used reacted with the airways in sections of lung from transgene $(-)$ mice, in great extent because of the lack of airway inflammation in these animals (data not shown). These observations demonstrate that these nodules are composed of large numbers of B lymphocytes and lesser numbers of CD4(+) and CD8(+) T cells.
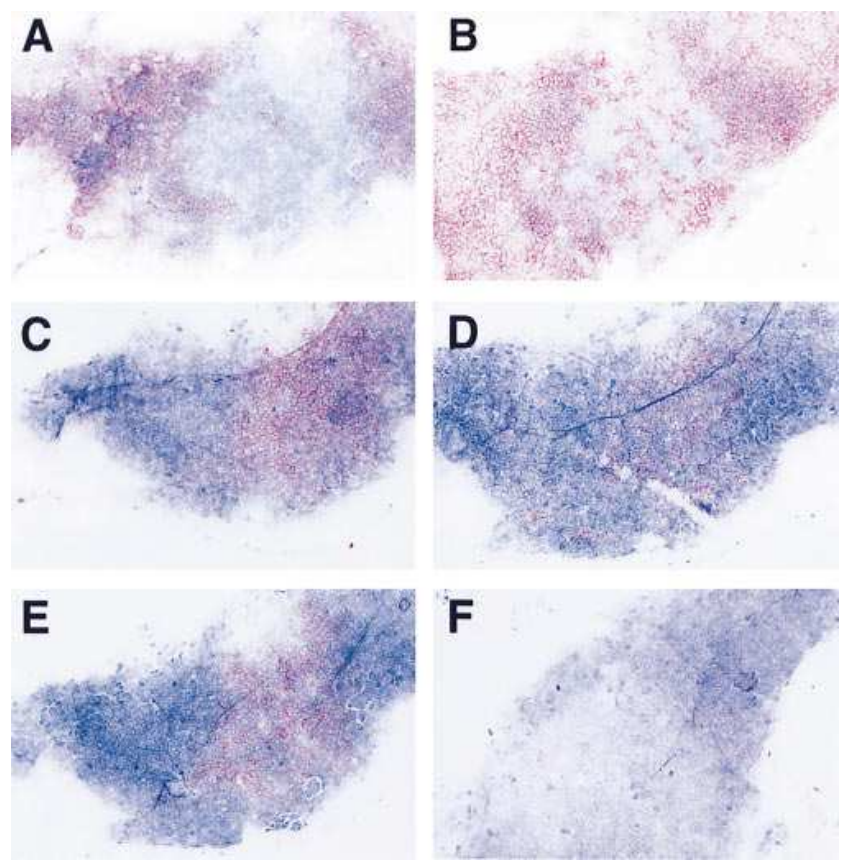

Figure 7. Immunohistochemistry of peribronchiolar nodular infiltrates. Immunohistochemical techniques were used to evaluate the cellular composition of the peribronchiolar infiltrates seen in the transgene $(+) \mathrm{CC} 10-\mathrm{IL}-11$ animals. Antibodies against B220 $(A)$, MHC class II $(B), \mathrm{CD} 3(C), \mathrm{CD} 4(D), \mathrm{CD} 8(E)$, and Mac-1 $(F)$ were employed. (Original magnification $50 \times$.)
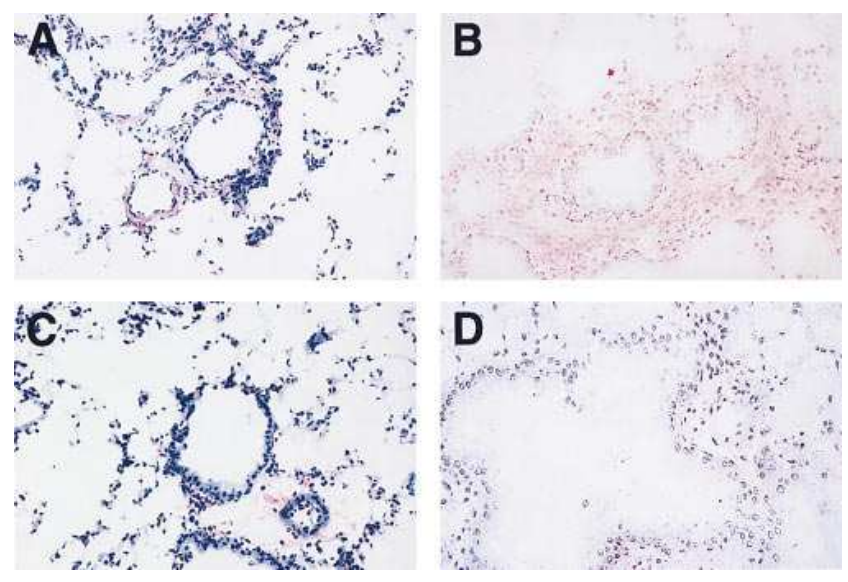

Figure 8. Immunohistochemical analysis of fibrotic response in CC10-IL-11 transgenic mice. Immunohistochemistry was used to evaluate the type I collagen in the airways of transgene $(+)(A)$ and $(-)(C)$ animals and the type III collagen in the airways of transgene $(+)(B)$ and $(-)(D)$ animals. (Original magnification $50 \times$.)

Composition of the subepithelial fibrotic response. Studies were undertaken to determine if types I or III collagen were increased in the airways of the transgene $(+)$ animals. These immunohistochemical evaluations demonstrated modest increases in type I collagen and impressive increases in type III collagen in transgene $(+)$ vs. $(-)$ animals (Fig. 8). Thus, the subepithelial fibrosis seen in CC10-IL-11 transgenic animals results, at least in part, from the increased accumulation of type III and, to a lesser extent, type I collagens.

Structural characterization of the transgenic airway. Immunohistochemistry and electron microscopy were used to further characterize the cellular and structural alterations in the airways of the CC10-IL-11 transgene $(+)$ animals. The immunohistochemical evaluations demonstrated an increase in the

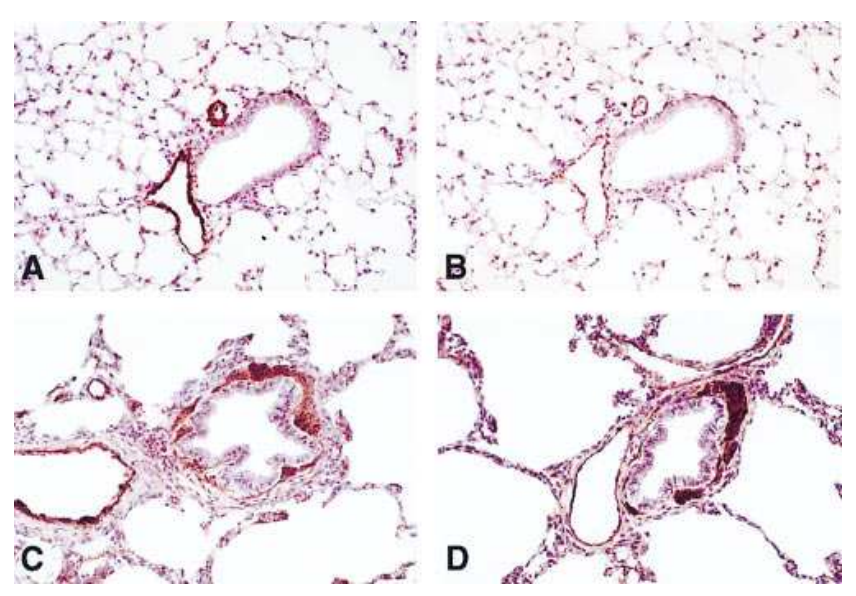

Figure 9. Immunohistochemical evaluation of subepithelial cellularity in CC10-IL-11 mice. Immunohistochemistry was used to evaluate the cellular components of the subepithelial fibrotic response in CC10-IL-11 transgene (+) and (-) animals. $A$ and $C$ represent the $\alpha$-smooth muscle actin immunoreactivity in transgene $(-)$ and $(+)$ animals, respectively. $B$ and $D$ represent the desmin immunoreactivity in transgene $(-)$ and $(+)$ animals, respectively. (Original magnification $50 \times$.) 

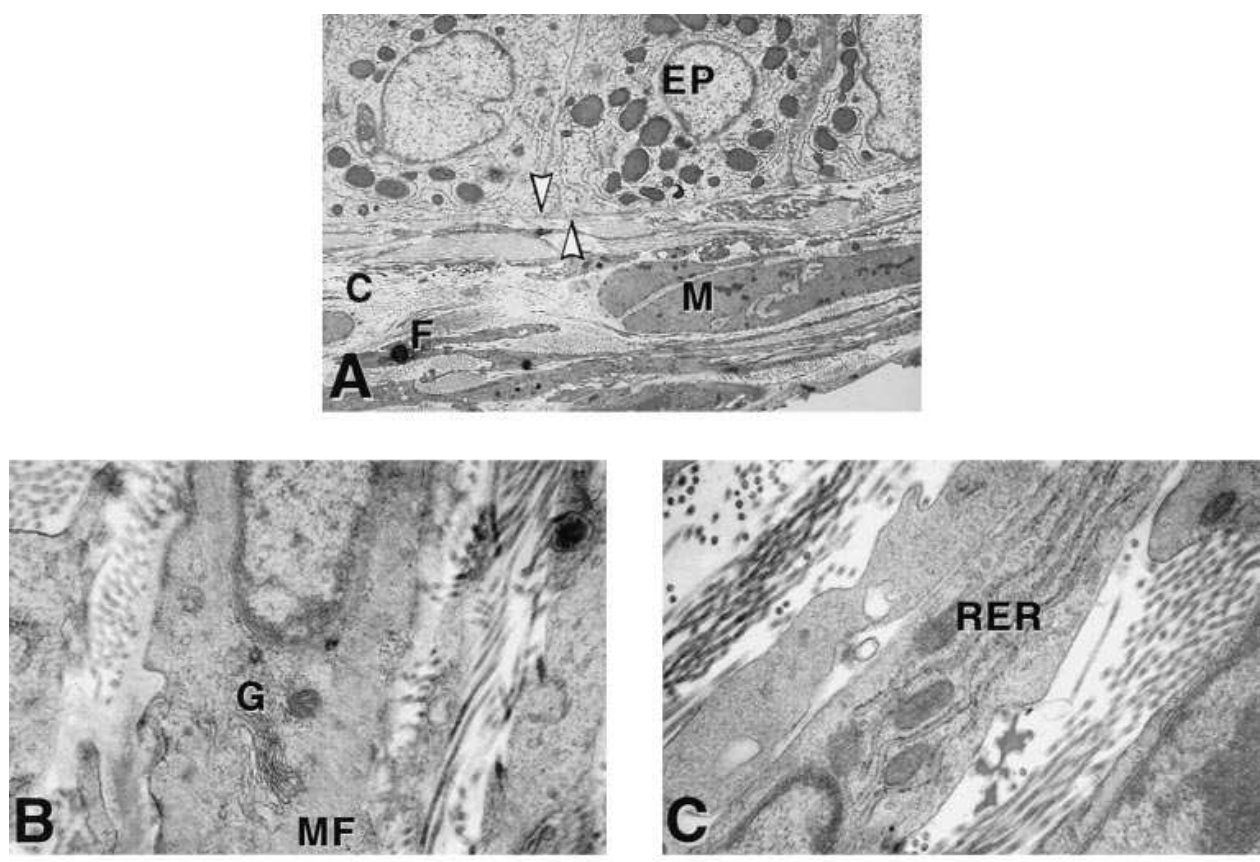

Figure 10. Electron microscopic appearance of peripheral airway of CC10-IL-11 mice. ( $A$ ) Low power view of airway wall with epithelial cells $(E P)$, myocytes $(M)$, and fibroblastic cells $(F)$. Note intact basement membrane (open arrows) and
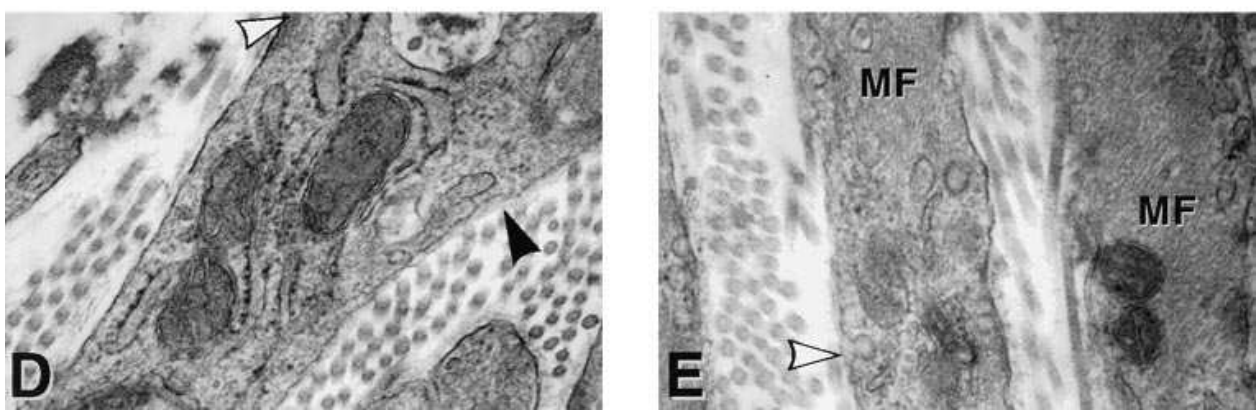
collagen deposition $(C)(4,000 \times)$. $(B)$ Smooth muscle cell with well formed $\operatorname{Golgi}(G)$. Note myofilaments $(M F)(18,000 \times) .(C)$ Fibroblast with rough endoplasmic reticulum $(R E R)$ $(18,000 \times) .(D)$ Myofibroblast with subplasmalemmal dense body (open arrow) and basal lamina (closed arrow) $(36,000 \times)$. (E) Myofibroblast with myofilaments $(M F)$ and subplasmalemmal vesicles (open arrow) $(36,000 \times)$.

number of $\alpha$ smooth muscle actin and desmin staining cells in the walls of the transgene (+) vs. $(-)$ animals (Fig. 9). This staining was not uniform, however, with some stromal cells failing to manifest either of these markers. The electron micrographs demonstrated that the CC10-IL-11 transgene (+) animals had normal basement membranes and enhanced striated collagen deposition (Fig. 10). They also demonstrated the accumulation of a variety of stromal cells in these fibrotic locations. Ultrastructurally, many cells appeared to be fibroblasts. Others appeared to be myofibroblasts based on their fibroblast-like appearance and the presence of myofilaments, dense bodies, subplasmalemmal vesicles, and/or identifiable basal lamina (Fig. 10 and data not shown). Smooth muscle cells with abundant myofilaments were also appreciated. Some of these cells showed morphologic evidence of increased synthetic activity with increased rough endoplasmic reticulum and prominent Golgi (Fig. 10). Thus, the subepithelial response in the airways of the CC10-IL-11 transgene (+) animals occurs in the absence of basement membrane thickening and is characterized by increased interstitial collagen deposition and heightened stromal cellularity with the local accumulation of fibroblasts, myofibroblasts, and smooth muscle cells.

Effect of IL-11 on airway physiology. Airways obstruction and hyperresponsiveness to nonspecific stimuli such as MCh are prominent features of asthma, COPD, and a variety of diseases characterized by chronic airways inflammation and/or fibrosis. Thus, studies were undertaken to characterize the physiologic profile of IL-11 transgene $(+)$ and $(-)$ animals. Overall, 18 age, sex, and weight matched littermate pairs were evaluated. The baseline airways resistance of IL-11 transgene $(+)$ animals greatly exceeded that of IL-11 transgene $(-)$ animals. At 2 mo of age, the airways resistance of the transgene $(+)$ animals was approximately threefold greater than the resistance of the transgene $(-)$ animals (745.3 \pm 227.5 vs. $227.5 \pm 6.4 \mathrm{~cm} \mathrm{H}_{2} \mathrm{O} /$ liters per s; $\left.P<0.05\right)$. In addition, 1.5-2mo-old transgene $(+)$ animals manifest exaggerated sensitivity to methacholine since they achieved a $100 \%$ increase in airways resistance at $1 / 10$ to $1 / 100$ the dose of methacholine required by their transgene (-) littermate controls (Fig. 11). When viewed in combination, these studies demonstrate that IL-11 transgene $(+)$ animals manifest increased airways resistance and airways hyperresponsiveness to $\mathrm{MCh}$ when compared with transgene $(-)$ littermate controls.

\section{Discussion}

Airway inflammation and fibrosis are prominent features of a variety of disorders including asthma, COPD, bronchiectasis, and bronchiolitis (3-11). In these disorders, the relationship(s) between inflammation, fibrosis, and physiologic dysregulation, and the contribution that individual mediators make to the pathogenesis of these abnormalities are poorly understood. 


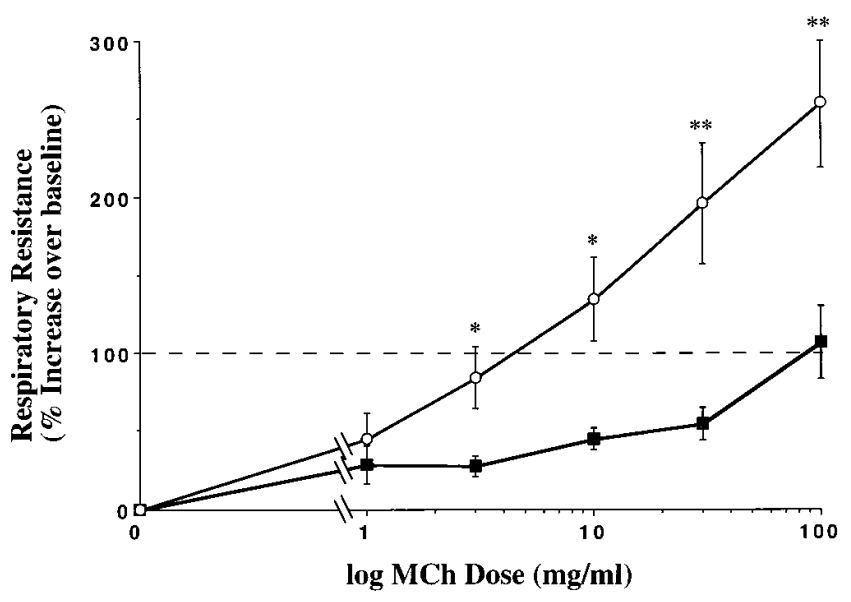

Figure 11. Methacholine sensitivity of transgene (-) and (+) mice. The effect of varying concentrations of methacholine on the airways resistance of paired transgene $(+)(\bigcirc)$ and transgene $(-)(\boldsymbol{\square})$ littermates were evaluated as described in Methods. Values represent the mean \pm SEM of six age and sex matched littermates evaluated on the same day $(* P<0.05, * * P<0.01, t$ test $)$.

This is due, in great extent, to the complexity of the inflammatory and fibrotic responses in these disorders, which precludes the clear attribution of cause and effect. It is also the result of our need to rely on in vitro and acute challenge in vivo protocols in our modeling of these disorders. The limitations of our present approach are nicely illustrated with IL-11. In vitro studies from our laboratory and others have clearly demonstrated that this cytokine is produced by a variety of stromal cells, including airway and alveolar epithelial cells, after incubation with cytokines $(21,30)$, histamine $(31)$, and respiratory viruses $(21,23)$. These studies have also demonstrated that IL-11 can be found in abnormal quantities at sites of human viral respiratory tract infection, and acute studies have demonstrated that IL-11 causes AHR in vivo (23). In contrast, the chronic effects of IL-11 in the lung or other visceral organs have not been characterized. To gain insight into the role that IL-11 might play in chronic inflammatory airway disorders such as asthma, COPD, bronchiectasis, and bronchiolitis, we used the CC10 promoter to chronically express IL-11 in the murine airway. These studies demonstrate that IL-11 induces a nodular lymphocytic peribronchial and peribronchiolar inflammatory response. They also demonstrate, for the first time, that IL-11 is a fibrogenic cytokine since it caused impressive airway remodeling with subepithelial fibrosis and the local accumulation of fibroblasts, myofibroblasts, and smooth muscle cells. Lastly, these studies demonstrate that these pathologic abnormalities are associated with prominent physiologic dysfunction with airways obstruction and AHR to methacholine.

IL-11 was initially discovered as an IL-6-like plasmacytoma proliferation stimulating activity in fibroblast-conditioned medium that could not be neutralized with antibodies against IL-6 (24). It has subsequently been shown to be an important hematopoietic growth factor (25), stimulate the acute phase response (25), augment immunoglobulin production $(25,28)$, induce the expression of metalloproteinase inhibitors $(26,27)$, regulate neural phenotype (29), regulate bone metabolism (40), and protect against the combined effects of radiation and chemotherapy (41). IL-11 and IL-6 are now grouped together as IL-6-type cytokines based on their overlapping functional profiles and shared use of the gp130 molecule in their multimeric receptor complexes (42). In keeping with these findings, a comparison of the phenotype of the CC10-IL-11 animals described in this report and CC10-IL- 6 mice described previously by our laboratories (32), shows interesting similarities and differences. The inflammatory response seen in both the IL-11 and IL-6 transgenic lines was almost exclusively lymphocytic and contained significant numbers of B cells. This is in keeping with the known B cell stimulatory activities of both of these cytokine moieties $(28,42,43)$. Interestingly, however, inflammation were more prominent in the CC10-IL-6 animals and airway remodeling and subepithelial fibrosis was more prominent in CC10-IL-11 animals. In addition, marked physiologic differences were noted with CC10-IL-6 animals manifesting normal baseline airways resistance and airways hyporesponsiveness to methacholine, while CC10-IL-11 animals demonstrated increased baseline airways resistance and AHR to methacholine. These findings clearly support the contention that the effects that are seen in these transgenic animals are cytokine specific and not merely the result of a murine immune response to transgenically expressed human protein. They also support, in a powerful fashion, the contention that different components of the inflammatory response, even cytokines in the same cytokine family with common receptor components, can have markedly different effects when chronically expressed in vivo. The power of this approach is also evident in this comparison since it allows correlations to be made between physiology and pathology. Specifically, these observations simultaneously demonstrate an association between airway remodeling and airways obstruction and hyperresponsiveness to methacholine, and a relative dissociation between inflammation and these physiologic abnormalities. These observations suggest that the remodeling process may be quite important and that the type of airway inflammation induced by IL- 6 is less important in the pathogenesis of these obstructive physiologic abnormalities.

Remodeling responses in the human airway, characterized by tissue fibrosis, matrix alterations, and quantitative and/or qualitative alterations of the structural and other resident cells that make up the airway wall are well documented in a variety of pulmonary pathologies $(3-5,8,9,11,44,45)$. These responses have been extensively studied in asthma where smooth muscle hyperplasia and hypertrophy are well documented $(44,45)$, and the "basement membrane thickening" that has been appreciated in asthmatic airway biopsies for decades is known to be due to the subepithelial deposition of type III collagen and other matrix molecules by activated airway myofibroblasts $(7,9)$. In contrast with other fibrotic pulmonary disorders, animal models of the airway fibrotic response are poorly developed and our knowledge of the role(s) that mediators play in the generation of airway scarring is rudimentary. This study demonstrates that IL-11 is a fibrogenic molecule and describes, for the first time, an animal model that reproduces many of the important features of the remodeled asthmatic airway. Specifically, it demonstrates that the targeted expression of IL-11 in the murine airway causes prominent subepithelial fibrosis with impressive increases in type III and to a lesser extent type I collagen. In addition, it demonstrates that this response occurs in the absence of overt basement membrane pathology and contains increased numbers of a variety of stromal cells, including airway myofibroblasts. This 
study did not address the mechanism(s) responsible for this fibrotic response. There are, however, a number of possible pathways that deserve comment. First, IL-11 is known to stimulate the production of tissue inhibitor of metalloproteinase-1 $(26,27)$. Tissue inhibitor of metalloproteinase-1 decreases collagen degradation and thus could contribute to collagen accumulation and tissue fibrosis. Second, studies from this and other laboratories have demonstrated that TGF- $\beta$ is a potent stimulator of IL-11 production $(26,30)$. This raises the possibility that fibrogenic effector functions of TGF- $\beta$, such as its stimulation of collagen production and $\alpha$-smooth muscle actin accumulation (46), may also be mediated by IL-11. Additional investigation will be required to sort out these possibilities.

In previous years, an intrinsic abnormality of the airway myocyte was felt to be at the heart of the asthmatic diathesis. More recent studies have revised this concept and led to a renewed appreciation of the role of inflammation and tissue fibrosis in this disorder (6-9). As a result of these studies it is now known that a chronic eosinophilic and mononuclear cellpredominant inflammatory response, epithelial injury and desquamation, and subepithelial fibrosis are prominent features of the pathology of asthma. In addition, it is now assumed that the inflammation and epithelial injury are largely responsible for the physiologic abnormalities characteristic of this disorder. Our studies, however, add an additional layer of complexity to these concepts. First, they raise questions about the link between inflammation and AHR since prominent physiologic dysregulation was seen in the CC10-IL-11 animals that manifest only a mild nodular peribronchiolar lymphocytic response. Second, they raise questions about the importance of eosinophils since they demonstrate that AHR and airways obstruction are seen in CC10-IL-11 animals in the absence of prominent tissue eosinophilia. Lastly, they raise questions about the importance of epithelial desquamation in this disorder since CC10-IL-11 animals manifest prominent physiologic dysregulation in the absence of this abnormality. These questions are, however, not without precedent since a growing body of data from this and other laboratories has shown a dissociation between inflammation, eosinophil infiltration, epithelial desquamation, and physiologic dysregulation in human asthma and animal models of the asthmatic diathesis $(32,47-50)$. They are also in accord with the well established observation that airways obstruction and/or AHR are prominent features of airways disorders such as bronchitis, bronchiectasis, and endobronchial sarcoidosis, which are not characterized by eosinophilia or epithelial sloughing $(10,51,52)$. When viewed in combination, these observations suggest that a variety of different pathogenic processes can lead to airways obstruction and AHR and that different processes may be operative in different disorders.

Viruses are being increasingly appreciated to play an important role in the pathogenesis of asthma and other airway disorders. RSV is the most common cause of infantile bronchiolitis (10), RSV, PIV3, and rhinovirus are major inducers of asthmatic exacerbations in children and adults (12-15), and infantile viral infections are strongly associated with the development of asthma and COPD in later life $(12,13,17,19)$. The mechanisms behind these associations are, however, poorly understood. Previous data from our laboratory demonstrated that rhinovirus, RSV, and PIV3 are potent inducers of IL-11 production in vitro $(21,23)$. This contrasts with the inability of other pneumotropic infectious agents to similarly induce the production of this cytokine, and suggests that IL-11 plays an important role in the pathogenesis of these viral disorders. The demonstration in these studies that IL-11 causes lymphocytic infiltration, airway remodeling, and physiologic dysfunction has obvious relevance to the pathogenesis of viral airways disorders. The impressive similarities between some of the airway and physiologic alterations seen in the CC10-IL-11 transgenic mice and neonatal rats with experimental PIV-1 infection (53) further supports the contention that IL-11 is involved in mediating these abnormalities. It allows for the tantalizing speculation that neonatal viral infections predispose to chronic airways dysfunction at least in part via the induction of IL-11 production, which causes lymphocytic infiltration and airway remodeling. When coupled with the observation that IL-11 inhibits human macrophage IL-12 production (S.X. Leng, Department of Internal Medicine, Yale University; and J.A. Elias, unpublished observations), one is left with the interesting possibility that IL-11 production during neonatal and/or pediatric viral infections can also predispose to the development of the $\mathrm{Th}_{2}$ lymphocytic response that is felt to play a key role in the asthmatic diathesis (54).

In conclusion, our studies demonstrate that the transgenic expression of IL-11 in the mouse airway results in a nodular lymphocytic infiltrate, airway remodeling, and physiologic dysregulation that mimics in important ways the pathologic and physiologic features of viral and other airways disorders. These findings suggest that IL-11 may play an important role in the pathogenesis of the airways abnormalities seen in these often times devastating disorders. In this respect, CC10-IL-11 transgenic mice represent an excellent animal model of airway remodeling and inflammation that can be used to explore therapies directed at these processes and the contribution that these processes make to the physiologic abnormalities seen in a variety of human airways disorders.

\section{Acknowledgments}

The authors thank the investigators and institutions that provided the reagents that were employed, Drs. Jeffery A. Whitsett and Barry Stripp for the gift of the CC10 promoter, Ms. Kathleen Bertier for her excellent secretarial assistance, and Mr. Ping Wang for his excellent technical assistance.

This work was supported by National Institutes of Health grants HL36708, HL-54989, and AI-34593 (J.A. Elias), and HL-3226 (G.P. Geba).

\section{References}

1. Weiss, K.B., P.J. Gergen, and T.A. Hodgson. 1992. An economic evaluation of asthma in the United States. N. Engl. J. Med. 326:862-866.

2. Lenfant, C., and S.S. Hurd. 1990. National asthma education program. Chest. 98:226-227.

3. Snider, G.L., J. Faling, and S.I. Rennard. 1994. Chronic bronchitis and emphysema. In Textbook of Respiratory Medicine. 2nd ed. J.F. Murray and J.A. Nadel, editors. W.B. Saunders Co., Philadelphia. 1331-1397.

4. Lazarus, S.C. 1994. Disorders of the intrathoracic airways. In Textbook of Respiratory Medicine. 2nd ed. J.F. Murray and J.A. Nadel, editors. W.B. Saunders Co., Philadelphia. 1471-1483.

5. Luce, J.M. 1994. Bronchiectasis. In Textbook of Respiratory Medicine. 2nd ed. J.F. Murray and J.A. Nadel, editors. W.B. Saunders Co., Philadelphia. 1398-1417.

6. Shelhamer, J.H., S.J. Levine, T. Wu, D.B. Jacoby, M.A. Kaliner, and S.I. Rennard. 1995. Airway inflammation. Ann. Intern. Med. 123:288-304.

7. Holgate, S.T., J.R. Wilson, and P.H. Howarth. 1992. New insights into airway inflammation by endobronchial biopsy. Am. Rev. Respir. Dis. 145:S2-S6.

8. Arm, J.P., and T.K. Lee. 1992. The pathology of bronchial asthma. Adv. Immunol. 51:323-382.

9. Brewster, C.E.P., P.H. Howarth, R. Djukanovic, J. Wilson, S.T. Holgate, 
and W.R. Roche. 1990. Myofibroblasts and subepithelial fibrosis in bronchial asthma. Am. J. Respir. Cell Mol. Biol. 3:507-511.

10. McIntosh, K., and R.M. Chanock. 1990. Respiratory syncytial virus. In Virology. 2nd ed. B.M. Fields and D.M. Knipe, editors. Raven Press, Ltd., New York. 1045-1072.

11. Gross, N.J. 1995. Airway inflammation in COPD, reality or myth? Chest. $107: 210 \mathrm{~s}-213 \mathrm{~s}$

12. Stark, J.M., and F.M. Graziano. 1995. Lower airway response to viruses. In Asthma and Rhinitis. W.W. Busse and S.T. Holgate, editors. Blackwell Scientific Publications, Boston. 1229-1243.

13. Pattemore, P.K., S.L. Johnston, and P.G. Bardin. 1992. Viruses as precipitants of asthma symptoms. I. Epidemiology. Clin. Exp. Allergy. 22:325-336.

14. Johnston, S.L., P.K. Pattemore, G. Sanderson, S. Smith, F. Lampe, L. Josephs, P. Symington, S. O'Toole, S.H. Myint, D.A.J. Tyrrell, and S.T. Holgate. 1995. Community study of role of viral infections in exacerbations of asthma in 9-11 year old children. Brit. Med. J. 310:1225-1228.

15. Nicholson, K.G., J. Kent, and D.C. Ireland. 1993. Respiratory viruses and exacerbations of asthma in adults. Brit. Med. J. 307:982-986.

16. Monto, A.S. 1995. Epidemiology of respiratory viruses in persons with and without asthma and COPD. Am. J. Respir. Crit. Care Med. 151:1653-1658.

17. Rooney, J.C., and H.E. Williams. 1971. The relationship between proved viral bronchiolitis and subsequent wheezing. J. Pediatr. 79:744-747.

18. Sigurs, N., R. Bjarnason, F. Sigurbergsson, B. Kjellman, and B. Bjorksten. 1995. Asthma and immunoglobulin antibodies after respiratory syncytial virus bronchiolitis: a prospective cohort study with matched controls. Pediatrics. 95:500-505.

19. Krzyzanowski, M., D.L. Sherrill, and D. Lebowitz. 1990. Longitudinal analysis of the effects of acute lower respiratory illnesses on pulmonary function in an adult population. Am. J. Epidemiol. 131:412-422.

20. Alwan, W.H., W.J. Kozlowska, and P.J.M. Openshaw. 1994. Distinct types of lung disease caused by functional subsets of antiviral T cells. J. Exp. Med. 179:81-89.

21. Elias, J.A., T. Zheng, O. Einarsson, M. Landry, T.K. Trow, N. Rebert, and J. Panuska. 1994. Epithelial interleukin-11: regulation by cytokines, respiratory syncytial virus and retinoic acid. J. Biol. Chem. 169:22261-22268.

22. Noah, T.L., and S. Becker. 1993. Respiratory syncytial virus-induced cytokine production by a human bronchial epithelial cell line. Am. J. Physiol. (Lung Cell. Mol. Physiol.) 265:L472-L478.

23. Einarsson, O., G.P. Geba, Z. Zhu, M. Landry, and J.A. Elias. 1996. Interleukin-11: stimulation in vivo and in vitro by respiratory viruses and induction of airways hyperresponsiveness. J. Clin. Invest. 97:915-924.

24. Paul, S.R., F. Bennett, J.A. Calvetti, K. Kelleher, C.R. Wood, R.M.J. Oharra, A.C. Leary, B. Sibley, S.C. Clark, D.A. Williams, and Y.-C. Yang. 1990. Molecular cloning of a cDNA encoding interluekin-11, a stromal cellderived lymphopoietic and hematopoietic cytokine. Proc. Natl. Acad. Sci. USA. 87:7512-7516.

25. Du, X.X., and D.A. Williams. 1994. Interleukin-11: a multifunctional growth factor derived from the hematopoietic microenvironment. Blood. 83: 2023-2030.

26. Maier, R., V. Ganu, and M. Lotz. 1993. Interleukin-11, an inducible cytokine in human articular chondrocytes and synoviocytes, stimulates the production of the tissue inhibitor of metalloproteinases. J. Biol. Chem. 268:2152721532.

27. Roeb, E., L. Graeve, R. Hoffmann, K. Decker, D.R. Edwards, and P.C. Heinrich. 1993. Regulation of tissue inhibitor of metalloproteinases-1 gene expression by cytokines and dexamethasone in rat hepatocyte primary cultures. Hepatology. 18:1437-1442.

28. Yin, T., P. Schendel, and Y.-C. Yang. 1992. Enhancement of in vitro and in vivo antigen-specific antibody responses by IL-11. J. Exp. Med. 175:211-216.

29. Fann, M.-J., and P.H. Patterson. 1994. Neuropoietic cytokines and activin A differentially regulate the phenotype of cultured sympathetic neurons. Proc. Natl. Acad. Sci. USA. 91:43-47.

30. Elias, J.A., T. Zheng, N.L. Whiting, T.K. Trow, W.W. Merrill, R. Zitnik, P. Ray, and E.M. Alderman. 1994. Interleukin-1 and transforming growth factor $\beta$ regulation of fibroblast-derived interleukin-11. J. Immunol. 152:2421-2429.

31. Zheng, T., M. Nathanson, and J.A. Elias. 1994. Histamine augments cytokine-stimulated interleukin-11 production by human lung fibroblasts. J. Immunol. 153:4742-4752.

32. DiCosmo, B.F., G.G. Geba, D. Picarella, J.A. Elias, J.A. Rankin, B.R. Stripp, J.A. Whitsett, and R.A. Flavell. 1994. Airway targeted interleukin-6 in transgenic mice: uncoupling of airway inflammation and bronchial hyperreactivity. J. Clin. Invest. 94:2028-2035.

33. Pack, R.J., L.H. Al-Ugaily, and G. Morris. 1981. The cells of the tra- cheo-bronchial epithelium of the mouse: a quantitative light and electron microscope study. J. Anat. 132:71-84.

34. Stripp, B.R., P.L. Sawaya, D.S. Luse, K.A. Wikenheiser, S.E. Wert, J.A Huffman, D.L. Lattier, G. Singh, S.L. Katyal, and J.A. Whitsett. 1992. Cis-acting elements that confer lung epithelial cell expression of the CC10 gene. J. Biol. Chem. 267:14703-14712.

35. Hogan, B., F. Constantini, and E. Lacy. 1986. Manipulating the mouse embryo: a laboratory manual. Cold Spring Harbor Laboratory, Cold Spring Harbor, New York.

36. Elias, J.A., W. Tang, and M.C. Horowitz. 1995. Cytokine and hormonal stimulation of osteosarcoma interleukin-11 production. Endocrinology. 136: 489-498.

37. Zhu, Z., W. Tang, A. Ray, Y. Wu, O. Einarsson, M. Landry, J. Gwaltney, and J.A. Elias. 1996. Rhinovirus stimulation of interleukin-6 in vivo and in vitro: evidence for NF-кB-dependent transcriptional activation. J. Clin. Invest. 97:421-430.

38. Martin, T., N. Gerard, S. Galli, and J. Drazen. 1988. Pulmonary responses to bronchoconstrictor agonists in the mouse. J. Appl. Physiol. 64:23182323

39. Amdur, M.O., and J. Mead. 1958. Mechanics of respiration in unanesthetized guinea pigs. Am. J. Physiol. 192:364-368

40. Girasole, G., G. Passeri, R.L. Jilka, and S.C. Manolagas. 1994. Interleukin-11: a new cytokine critical for osteoclast development. J. Clin. Invest. 93: 1516-1524.

41. Du, X.X., C.M. Doerschuk, A. Orazi, and D.A. Williams. 1994. A bone marrow stromal-derived growth factor, interleukin-11, stimulates recovery of small intestinal mucosal cells after cytoablative therapy. Blood. 83:33-37.

42. Zhang, X.-G., J.-J. Gu, K. Yasukawa, G.D. Yancopoulos, K. Turner, M. Shoyab, T. Taga, T. Kishimoto, R. Bataile, and B. Klein. 1994. Ciliary neurotropic factor, interleukin 11, leukemia inhibitory factor, and oncostatin $\mathrm{M}$ are growth factors for human myeloma cell lines using the interleukin 6 signal transducer gp130. J. Exp. Med. 177:1337-1342.

43. Suematsu, S., T. Matsuda, K. Aozasa, S. Akira, N. Nakano, S. Ohno, J.-I. Miyazaki, K.-I. Yamamura, T. Hirano, and T. Kishimoto. 1989. IgG1 plasmacytosis in interleukin 6 transgenic mice. Proc. Natl. Acad. Sci. USA. 86:75477551.

44. Hossain, S. 1973. Quantitative measurement of bronchial muscle in men with asthma. Am. Rev. Respir. Dis. 107:99-109.

45. Ebina, M., T. Takahashi, T. Chiba, and M. Motomiya. 1993. Cellular hypertrophy and hyperplasia of airway smooth muscles underlying bronchial asthma. Am. Rev. Respir. Dis. 148:720-726.

46. Desmouliere, A., A. Geinoz, F. Gabbiani, and G. Gabbiani. 1993. Transforming growth factor- $\beta_{1}$ induces $\alpha$-smooth muscle actin expression in granulation tissue myofibroblasts and in quiescent and growing cultured fibroblasts. J. Cell Biol. 122:103-111.

47. Brugman, S.M., G.L. Larsen, P.M. Henson, J. Honor, and C.G. Irvin 1993. Increased lower airways responsiveness associated with sinusitis in a rabbit model. Am. Rev. Respir. Dis. 147:314-320.

48. Corry, D.B., H.G. Folkesson, M.L. Warnock, D.J. Erle, M.A. Matthay, J.P. Weiner-Kronish, and R.M. Locksley. 1996. Interleukin-4, but not interleukin 5 or eosinophils, is required in a murine model of acute airway hyperreactivity. J. Exp. Med. 183:109-117.

49. Pattemore, P.K., M.I. Asher, A.C. Harrison, E.A. Mitchell, H.H. Rea, and A.W. Stewart. 1990. The interrelationship among bronchial hyperresponsiveness, the diagnosis of asthma, and asthma symptoms. Am. Rev. Respir. Dis. 142:549-554.

50. Swiecichowski, A.L., K.J. Long, M.L. Miller, and G.D. Leikauf. 1995. Formaldehyde-induced airway hyperreactivity in vivo and ex vivo in guinea pigs. Environ. Res. 310:1229-1231.

51. Pang, J., H.S. Chan, and J.Y. Sung. 1989. Prevalence of asthma, atopy, and bronchial hyperactivity in bronchiectasis: a controlled study. Thorax. 44 948-951.

52. Levinson, R.S., L.F. Metzger, N.N. Stanley, S.G. Kelsen, M.D. Altose, N.S. Cherniack, and J.S. Brody. 1977. Airway function in sarcoidosis. Am. J. Med. 62:51-59.

53. Castleman, W.L., R.L. Sorkness, R.F. Lemanske, G. Grasee, and M.M. Suyemoto. 1988. Neonatal viral bronchiolitis and pneumonia induces bronchiolar hypoplasia and alveolar dysplasia in rats. Lab. Invest. 59:387-396.

54. Robinson, D.S., Q. Hamid, S. Ying, A. Tsicopoulos, J. Barkans, A.M Bentley, C. Corrigan, S.R. Durham, and A.B. Kay. 1992. Predominant Th2-like bronchoalveolar T-lymphocyte population in atopic asthma. N. Engl. J. Med. 326:298-304. 